\title{
Diagnóstico e estudo sorológico da infeç̧ão pelo parvovírus canino em cães de Passo Fundo, Rio Grande do Sul, Brasil
}

\author{
Diagnosis and serological study of canine parvovirus infection in dogs from Passo Fundo, \\ Rio Grande do Sul, Brazil
}

\author{
Daisy Maria Strottmann' ${ }^{\mathrm{I}}$ Gabriela ScortegagnaII Luiz Carlos Kreutz ${ }^{\mathrm{II}}$ \\ Leonardo José Gil Barcellos ${ }^{\text {II }}$ Rafael Frandoloso ${ }^{\text {II }}$ Deniz Anziliero ${ }^{\text {II }}$
}

\section{RESUMO}

A reação em cadeia da polimerase (PCR) e o ensaio de hemaglutinação (HA) foram comparados para a identificação de parvovírus canino (CPV) em fezes de cães com gastrenterite. A prevalência de anticorpos anti-CPV em uma população de cães sem histórico de vacinação foi avaliada pelo ensaio de inibição da hemaglutinação (HI). A variabilidade fenotípica entre uma amostra vacinal e isolados de campo foi investigada utilizando soro hiperimune. Trinta amostras fecais foram obtidas de cães com diarréia e submetidas à PCR e ao HA, e 185 amostras de soro de cães foram submetidas à HI para detectar anticorpos anti-CPV. Considerando-se somente como positivas as amostras que apresentaram HA na diluição igual ou superior a 1:64, detectou-se CPV em 9 (30\%) das amostras fecais. Nove amostras fecais apresentaram HA nas diluições entre 1:2 e 1:32 e foram consideradas negativas nesse teste. Todas as amostras que apresentaram HA na diluição igual ou superior a 1:64 foram positivas pela PCR e, das nove amostras que apresentaram HA nas diluições entre 1:2 e 1:32, seis também foram positivas para CPV na amplificação pela PCR. A pesquisa sorológica de amostras de soros caninos indicou que 178 (96,2\%) cães tiveram contato prévio com o vírus. Os soros hiperimunes produzidos em cobaias contra a cepa vacinal e dois isolados de campo indicaram possíveis diferenças fenotípicas entre isolados.

Palavras-chave: parvovírus canino, gastrenterite, diagnóstico, hemaglutinação, reação em cadeia da polimerase

\section{ABSTRACT}

The polymerase chain reaction (PCR) and hemaglutination (HA) assay were used to detect canine parvovirus $(C P V)$ in feces from young dogs with gastroenteritis.
The hemaglutination inhibition (HI) assay was used to detect the prevalence of anti-CPV antibodies in a non-vaccinated dog population. In addition, hiperimmune serum was used to investigate the phenotypic variability of a vaccine strain and two field isolates of CPV. Thirty fecal samples obtained from dogs with diarrhea were submitted to PCR and HA, and 185 serum samples were submitted to $H I$ to detect anti-CPV antibodies. Nine (30\%) of the samples demonstrated HA on fecal dilutions equal to or above 1:64 and were considered positive by this test; nine (30\%) fecal samples had HA activity on dilution from $1: 2$ to $1: 32$ and were considered negative, and the remaining samples were negative. All samples with HA activity at dilutions above 1:64 were also positive to PCR and, out of the nine samples with HA activity at dilutions between 1:2 and 1:32, six were also positive by PCR. Serological analysis of the dog serum samples indicated that 178 (96,2\%) of the dogs had previous contact with the virus. Hiperimmune serum indicated possible phenotypic differences among isolates, in that different HI titers were obtained following cross-HI assay.

Key words: canine parvovirus, gastroenteritis, diagnosis, haemagglutination, polymerase chain reaction.

\section{INTRODUÇÃO}

A parvovirose canina é uma das mais importantes infecções virais de cães jovens. Clinicamente, a enfermidade manifesta-se por febre, vômitos, diarréia, freqüentemente hemorrágica, rápida desidratação e alta mortalidade. O agente etiológico da parvovirose canina é um vírus DNA, não-envelopado, pertencente à família Parvoviridae, genêro Parvovirus (MURPHY et al., 1999), denominado parvovírus canino

IPrograma de Pós-graduação do Instituto de Biologia Molecular do Paraná, Curitiba, PR, Brasil.

ILaboratório de Virologia e Imunologia, Hospital Veterinário, Faculdade de Agronomia e Medicina Veterinária (FAMV),Universidade de Passo Fundo (UPF). Campus I, Bairro São José, CP 611, 99001-970, Passo Fundo, RS, Brasil. Fone/Fax: (54) 3316 8444/3316 8487. E-mail: lckreutz@upf.tche.br. *Autor para correspondência. 
(CPV). Atualmente, existem dois parvovírus de cães: o CPV tipo 1, também denominado parvovírus diminuto dos cães (CnMV), sem importância clínica definida nas gastrenterites, e o CPV-2, que apresenta três subtipos - CPV2a, CPV2b e CPV2c. O CPV2b é o mais prevalente na população canina e, conseqüentemente, utilizado em vacinais (TRUYEN, 2006).

Os sinais clínicos da infecção são típicos e o diagnóstico clínico da infecção é apoiado por exames sanguíneos nos quais predomina intensa leucopenia. No entanto, existem outros agentes causadores de gastrenterite e que freqüentemente induzem erro no diagnóstico e, conseqüentemente, podem sub ou superestimar a prevalência da parvovirose em relação a outras enfermidades com sinais clínicos semelhantes.

O diagnóstico definitivo da parvovirose consiste na identificação do CPV nas fezes de cães infectados, por meio de testes como a hemaglutinação, o ensaio imunoenzimático, a aglutinação em látex (VEIJALAINEN et al., 1986), a reação em cadeia da polimerase (PCR) (MOCHIZUKI et al., 1993; UWATOKO et al., 1995) e o isolamento viral (VI) em cultivo celular (MOCHIZUKI \& HASHIMOTO, 1986). Embora o isolamento em cultivo celular seja considerado o teste padrão, a PCR e a HA têm sido amplamente utilizadas principalmente pela alta especificidade e praticidade destes testes.

As gastrenterites de cães jovens são comuns em todas as regiões do Brasil (GARCIA et al., 2000). No entanto, na cidade de Passo Fundo e região, não se tem conhecimento de dados relativos ao diagnóstico, à soroprevalência e ao genótipo prevalente do CPV. O presente trabalho teve como objetivo identificar o CPV em fezes de cães jovens com diarréia, utilizando as técnicas de HA e PCR, comparar a sensibilidade e a praticidade de utilização dessas técnicas de diagnóstico, verificar variações fenotípicas entre o CPV vacinal e isolados de campo e avaliar a prevalência de anticorpos anti-CPV em cães sem histórico de vacinação na cidade de Passo Fundo, RS.

\section{MATERIAL E MÉTODOS}

Foram analisadas 30 amostras fecais de cães com diarréia, coletadas entre dezembro de 2004 e março de 2005, diluídas (1:10 v/v) em solução de Hank's (pH 7,3). Após centrifugação (1500 x g/10 minutos), o sobrenadante foi removido e tratado com clorofórmio $(1: 10 \mathrm{v} / \mathrm{v})$ a $4^{\circ} \mathrm{C}$, por dez minutos. Após nova centrifugação, o sobrenadante foi aliquotado e estocado a $-10^{\circ} \mathrm{C}$ até o momento das análises. Amostras de sangue de 185 cães de diferentes idades e raças, sem histórico de vacinação, foram coletadas em 14 diferentes bairros do município de Passo Fundo, durante a campanha de vacinação anti-rábica de agosto de 2005. Anteriormente à coleta, aplicou-se um questionário epidemiológico e animais com histórico de vacinação contra CPV foram excluídos da amostragem. O sangue foi armazenado sob refrigeração até o momento da centrifugação (3000 x g, 10 minutos) para remoção do soro, que foi armazenado a $-20^{\circ} \mathrm{C}$ até ser testado.

O teste de hemaglutinação (HA) foi utilizado para identificar e quantificar o CPV. Para isso, utilizaramse placas de 96 cavidades com fundo em "U”, nas quais realizaram-se diluições seriadas (base 2) da suspensão fecal em igual volume de solução salina tamponada de borato (BBS; $\mathrm{H}_{3} \mathrm{BO}_{3} 0.5 \mathrm{M}$, NaOH 1.0M e $\mathrm{NaCl} 0.15 \mathrm{M}$, $\mathrm{pH} 9.0$ ) contendo $2 \%$ de soro fetal bovino (SFB). Após isso, acrescentou-se uma suspensão de eritrócitos de suíno a 0,5\% em diluente viral (VAD; $\mathrm{NaCl} 0.15 \mathrm{M}$, $\mathrm{Na}_{2} \mathrm{HPO}_{4} 0.3 \mathrm{M}, \mathrm{NaH}_{2} \mathrm{PO} 4 . \mathrm{H}_{2} \mathrm{O} 0.3 \mathrm{M}, \mathrm{pH}$ 6.0) e incubouse a $4^{\circ} \mathrm{C}$ durante duas horas (CARMICHAEL et al., 1980). Considerou-se como título viral da amostra a recíproca da maior diluição onde ocorreu a hemaglutinação.

O teste de inibição da hemaglutinação (HI) foi realizado para detectar anticorpos anti-CPV. Para tanto, realizaram-se diluições seriadas (base 10) do soro (inativado a $56^{\circ} \mathrm{C}$ e tratado com caolin a $25 \%$ e hemácias de suíno a 50\%) em igual volume de BBS, contendo $2 \%$ de SFB. Posteriormente, acrescentaram-se oito unidades HA (UHA) da amostra viral e incubou-se a placa em câmara úmida a $37^{\circ} \mathrm{C}$, durante duas horas. Após, adicionou-se uma suspensão de hemácias de suíno a $0,5 \%$ em VAD, seguida de incubação a $4^{\circ} \mathrm{C}$ por duas horas (SENDA et al., 1986). O título de anticorpos foi considerado a recíproca da maior diluição que inibiu a HA. A técnica de HI também foi utilizada para confirmar a identidade do CPV nas amostras fecais.

O soro hiperimune anti-CPV foi produzido em cobaias (Cavia porcellus) utilizando-se uma amostra vacinal e duas amostras de campo (UPF-06 e UPF-10). A primovacinação das cobaias foi realizada com uma mistura de vírus (1ml) e adjuvante completo de Freund (1ml), inoculada pela via subcutanea em 10 pontos distintos no dorso do animal (0,2ml/inoculação). Foram realizadas duas inoculações posteriores, com intervalo de 21 dias, sem adjuvante. As amostras sangüíneas foram coletadas das cobaias, sob anestesia, por meio de punção cardíaca, sete dias após a última inoculação. O soro hiperimune foi inativado $\left(56^{\circ} \mathrm{C} / 30\right.$ min.), diluído (1:5 v/v) em BBS e tratado com caolin a 25\% em BBS e hemácias de suíno a 50\% em VAD.

A Inoculação em cultivo celular foi realizada em células CRFK (Crandell-Reese Feline Kydney; 
ATCC, CCL-94) cultivadas com meio essencial mínimo (MEM), suplementado com 5\% de SBF (soro bovino fetal) e gentamicina (50mg L $\left.{ }^{-1}\right)$. As amostras fecais suspeitas para CPV foram inoculadas imediatamente após o repique das células, em placas de 24 cavidades. As células foram observadas por 96 horas para verificar a ocorrência de efeito citopático (ECP). Na ausência de ECP após a primeira inoculação, as células foram repassadas mais duas vezes antes de se descartar o material e considerá-lo negativo para CPV.

Na reação em cadeia da polimerase, os primers CPV3 (5'-GGGTGGAAATCACAGCAAC -3’) eCPV4(5'-AAATGGCCCTTGTGTAGACG -3') foram utilizados para amplificar um fragmento de 887 pares de base do gene que codifica as proteínas VP1/VP2 do CPV (NC_001539, GenBank; REED et al., 1988). Para a PCR, as amostras fecais já processadas foram diluídas (1:20 v/v) em água destilada estéril. A reação da PCR conteve 10pmol de cada primer, 2,5mM de $\mathrm{MgCl}_{2}, 1$ mM de dNTPs, tampão (1x) para a enzima, 5 U de Taq DNA Polimerase e 5 ul da amostra fecal, em um volume final de 50ul. A mistura foi levada ao termociclador (Minicycler ${ }^{\mathrm{Tm}}$ MJ Research) programado para uma desnaturação inicial $\left(95^{\circ} \mathrm{C} / 5 \mathrm{~min}\right)$ seguida de 30 ciclos de desnaturação $\left(94^{\circ} \mathrm{C} / 1 \mathrm{~min}\right)$, anelamento $\left(54^{\circ} \mathrm{C} / 1 \mathrm{~min}\right.$.) e extensão dos primers $\left(72^{\circ} \mathrm{C} / 1 \mathrm{~min}\right)$ e anelamento final ( $\left.72^{\circ} \mathrm{C} / 10 \mathrm{~min}\right)$. Como controle positivo, utilizou-se a amostra vacinal e, como controle negativo, utilizou-se água destilada. A análise dos fragmentos de DNA foi realizada por eletroforese em gel de agarose $(0,8 \%$ em TBE), sendo fragmentos corados com brometo de etídeo e visualizados sob a luz ultravioleta.

\section{RESULTADOS}

Os resultados obtidos com a HA foram comparados com aqueles obtidos pela PCR. Dentre as 30 amostras de fezes analisadas, nove (30\%) aglutinaram hemácias de suínos, com título igual ou superior a 64 UHA, e apresentaram-se específicas para CPV quando submetidas ao teste de HI com soro hiperimune anti-CPV. Todas as amostras com título superior a 32 foram também positivas na PCR, resultando em um fragmento de DNA de aproximadamente 887 pares de bases. A amostra vacinal utilizada como controle positivo apresentou títulos médios de 256 UHA e reação positiva na PCR. Nove amostras (30\%) apresentaram títulos hemaglutinantes entre 2 e 32 UHA e foram consideradas negativas pelo teste de HA. Destas, seis foram positivas ao PCR. Doze amostras (40\%) foram negativas ao teste de HA e pela PCR. Nos testes para determinação da sensibilidade da PCR, foram positivas todas as diluições da cepa vacinal até a diluição de 1:262.144.

Os títulos de anticorpos dos soros hiperimunes específicos contra CPV homólogos variaram de 2.560 a 20.480 unidades inibidoras da hemaglutinação (UHI). No entanto, ao se testar esses soros hiperimunes contra CPV heterólogos, obteve-se uma redução significativa nos títulos de anticorpos dos soros hiperimunes (Tabela 1). No soro de cães, os títulos de anticorpos anti-CPV variaram de zero a 20.480 UHI. A média geométrica dos títulos de anticorpos antiCPV neste estudo foi de 892 UHI. Dentre os 185 soros de cães analisados, sete (3,8\%) não apresentaram títulos de anticorpos contra CPV e 178 (96,2\%) foram positivos para anticorpos anti-CPV (Tabela 2). Os dados da prevalência dos títulos de anticorpos anti-CPV estão apresentados na figura 1 .

\section{DISCUSSÃO}

Clinicamente, as gastrenterites de origem infecciosa apresentam um quadro clínico semelhante (HOMEM et al.,1999). Freqüentemente, em cães com idade inferior a seis meses, a etiologia das gastrenterites hemorrágicas é atribuída principalmente ao CPV em detrimento de outros microorganismos. Nessas circunstâncias, são freqüentes as internações de cães jovens e com uma baixa imunidade materna, em isolamentos que possuem cães com suspeitas clínicas de cinomose, traqueobronquite infecciosa e/ou mesmo CPV. O diagnóstico precoce e definitivo da etiologia das gastrenterites caninas torna-se essencial para o tratamento e controle da disseminação do agente etiológico, principalmente se o CPV estiver envolvido,

Tabela 1 - Títulos de anticorpos dos soros hiperimunes, produzidos em cobaias, anti-CPV vacinal, anti-UPF-06 e anti-UPF-10 contra os vírus CPV vacinal, UPF-06 e UPF-10, determinado por inibição da hemaglutinação (HI) cruzada. O controle refere-se à amostra de soro coletada antes da imunização.

\begin{tabular}{|c|c|c|c|c|}
\hline \multirow{2}{*}{ Antígeno } & \multicolumn{4}{|c|}{ Título dos soros (HI) } \\
\hline & Anti-CPV vacinal & Anti-UPF-06 & Anti-UPF-10 & Controle \\
\hline CPV-vacinal & 20.480 & 2.560 & 40 & 0 \\
\hline UPF-06 & 1.280 & 10.240 & 1.280 & 0 \\
\hline UPF-10 & 1.280 & 5.120 & 2.560 & 0 \\
\hline
\end{tabular}


Tabela 2 - Anticorpos hemaglutinantes anti-CPV, detectados em amostras de soro de cães não-vacinados coletadas em agosto de 2005, no município de Passo Fundo, RS.

\begin{tabular}{lll}
\hline Título de anticorpos & $\begin{array}{c}\mathrm{N}^{\circ} \text { de soros/total } \\
\text { amostrado (\%) }\end{array}$ & $\begin{array}{c}\text { Média geométrica do } \\
\text { título de anticorpos } \\
\text { (IHA) }\end{array}$ \\
\hline$<10$ & $7 / 185(3,7)$ & 0 \\
$\geq 10 \leq 40$ & $22 / 185(11,9)$ & 30 \\
$>40 \leq 320$ & $84 / 185(45,4)$ & 181 \\
$>320 \leq 2.560$ & $65 / 185(35,1)$ & 1102 \\
$>2.560 \leq 20.480$ & $7 / 185(3,9)$ & 7608 \\
\hline
\end{tabular}

e para a alocação adequada de cães com outras infecções gastroentéricas. Nesse aspecto, a PCR vem sendo utilizada como método eficaz para o diagnóstico de inúmeras doenças de etiologia viral. Estudos anteriores demonstram que a PCR é mais específica e sensível para a detecção de CPV em fezes de cães, quando comparada com HA, ELISA e isolamento viral (MOCHIZUKI et al., 1993). Os dados obtidos no presente estudo corroboram esses dados e indicam que tanto a PCR quanto a HA são técnicas específicas e rápidas para a detecção de CPV em amostras fecais. Além disso, utilizando-se a PCR, foi possível detectar partículas virais até a diluição de 1: 262.144 de uma amostra vacinal contendo 256 UHA, o que evidencia a extrema sensibilidade da PCR em comparação com a HA (dados não apresentados).

No presente estudo, as mesmas amostras utilizadas para PCR foram também inoculadas em cultivo de células CRFK. Amostras fecais com alto título hemaglutinante apresentaram efeito citopatogênico
(ECP) 24 a 36 horas após a inoculação. Amostras com baixo título viral necessitaram de passagens sucessivas e eventualmente não foi possível determinar a ocorrência de ECP (dados não apresentados). $\mathrm{O}$ insucesso no isolamento viral a partir de amostras com baixo título viral ocorre principalmente em razão de o CPV replicar somente em células mitoticamente ativas, ou seja, logo após o repique celular. Conseqüentemente, após a formação do tapete celular, é possível que não se obtenha mais um número suficientemente grande de células em replicação para suportar a replicação viral, possibilitando a perda do inóculo por diluição.

Uma ocorrência de HA nas diluições de fezes abaixo de 1:64 pode eventualmente indicou que estas sejam negativas para CPV, devido à possibilidade da ocorrência de aglutinação inespecífica (CARMICHAEL, 1980). Nesse trabalho, no entanto, não foi possível estabelecer uma relação entre gravidade da infecção e título de HA. Por outro lado, pelo menos um caso de gastrenterite hemorrágica resultou negativo para CPV em todas as técnicas de diagnóstico utilizadas, o que evidencia a necessidade de investigação mais profunda de outras causas de diarréias hemorrágicas. No presente trabalho, apenas 56,7\% (17/30) das gastrenterites caninas foram causadas pelo CPV, o que demonstra que um diagnóstico baseado apenas nos sinais clínicos certamente proporcionará um manejo incorreto do paciente e tratamento inadequado da doença.

O estudo fenotípico por meio de soro hiperimune e HI cruzada permitiu identificar diferenças entre duas amostras de campo de CPV e uma amostra

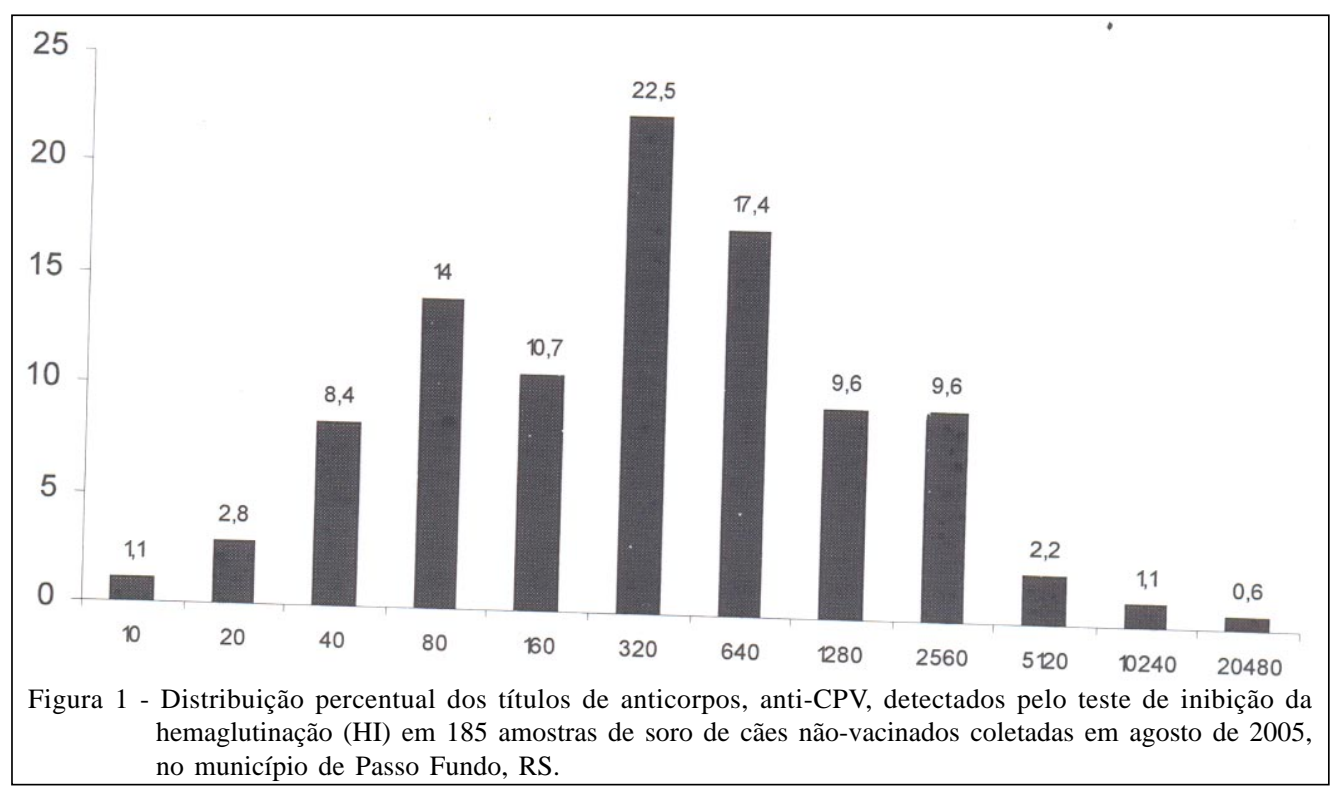

Ciência Rural, v.38, n.2, mar-abr, 2008. 
vacinal. Dados semelhantes foram observados anteriormente por soroneutralização cruzada utilizando soro hiperimune contra CPV-2 e CPV2b (PRATELLI et al., 2001). É possível que essas diferenças fenotípicas sejam decorrentes de pequenas variações nos epitopos das proteínas estruturais dos vírus, ocasionadas por discretas mutações genéticas (PARRISH et al., 1991; TRUYEN et al., 1995; SAGAZIO et al., 1998). Embora o significado dessa variabilidade ainda seja investigado, acredita-se que tenha importância principalmente quando os filhotes, com imunidade passiva materna, são desafiados com vírus antigenicamente diferente, ou seja, um determinado título de anticorpos é suficientemente alto para proteger contra o desafio com o vírus homólogo, mas não o suficiente para evitar uma infecção por uma cepa heteróloga, podendo causar doença nesses cães (TRUYEN, 2006). No entanto, as possíveis diferenças entre essas cepas somente poderão ser identificadas através do seqüenciamento genético das amostras de CPV analisadas neste estudo.

Atualmente, com o uso de vacinas contra a parvovirose canina, a infecção por CPV tem sido relativamente controlada. No entanto, os dados sorológicos obtidos neste estudo demonstram que 96,2\% (178/185) dos cães analisados apresentaram títulos de anticorpos contra CPV vacinal entre 10 e 20.480 UHI, ressaltando-se que a maior prevalência dos títulos, 22,5\% (40/178), foi de 320 UHI. Estudos prévios demonstram que cães com títulos de anticorpos contra CPV superiores a 80 UHI são imunes à infecção oronasal por CPV (POLLOCK \& CARMICHAEL, 1982). Títulos de anticorpos abaixo de 80 UHI não conferem proteção contra a infecção por CPV, além de interferiram na imunização ativa do animal (PRATELLI et al., 2001). Entre os cães estudados, 29 (15,6\%) apresentam títulos de anticorpos abaixo de 80 (Tabela 2). A infecção pelo CPV nesses animais pode se tornar um problema caso ocorra em uma fêmea em gestação, manifestando-se na forma de abortos, ou em seus filhotes, que, devido à baixa quantidade de anticorpos anti-CPV da mãe, não recebem quantidades suficientes de anticorpos maternos via colostro e leite e se tornam, conseqüentemente, suscetíveis à infecção antes de se iniciar um programa de vacinação.

Em resumo, os dados obtidos no presente trabalho evidenciam a necessidade de um diagnóstico diferencial rápido das gastrenterites caninas, que pode ser realizado pela HA ou pela PCR. Estudos fenotípicos sugerem possíveis diferenças genotípicas que deverão ser avaliadas por meio de sequenciamento genético. Embora o CPV se encontre amplamente disseminado, uma parcela significativa de cães possui títulos de anticorpos não protetores e alguns são soronegativos, o que permite a contínua circulação do CPV e a manutenção do caráter endêmico dessa infecção.

\section{AGRADECIMENTOS}

Os autores agradecem ao MSc. Sérgio Porto, do Biotério da Universidade de Passo Fundo, RS, pela colaboração na manipulação dos animais de laboratório, e aos acadêmicos de Medicina Veterinária que auxiliaram na coleta das amostras. LCK é bolsista PQ do CNPq (300259/2003-4).

\section{REFERÊNCIAS}

CARMICHAEL, L.E. et al. Haemagglutination by canine parvovirus: serologic studies and diagnostic application. American Journal of Veterinary Research, v.41 n.5, p.784791, 1980 .

GARCIA, R.C.N.C. et al. Canine parvovirus infection in puppies with gastroenteritis in Niterói, Rio de Janeiro, Brazil from 1995 to 1997. Brazilian Journal of Veterinary Research and Animal Science, v.37, n.2, p.56-68, 2000.

HOMEM, V.S.F. et al. Gastrenterite canina - agentes virais nas fezes de cães diarréicos e não diarréicos. Arquivo Brasileiro de Medicina Veterinária e Zootecnia, v.51, n.6, p.42-53, 1999.

MOCHIZUKI, M.; HASHIMOTO, T. Growth of feline panleukopenia virus and canine parvovirus in vitro. Japanese Journal of Veterinary Science, v.48, n.4, p.841-844, 1986.

MOCHIZUKI, M. et al. Comparison of polymerase chain reaction with virus isolation and haemagglutination assays for the detection of canine parvoviruses in faecal specimens. Research in Veterinary Science, v.55, p.60-63, 1993.

MURPHY, F.A. et al. Veterinary virology. 3.ed. New York: Academic, 1999. 629p.

NUCLEOTIDE SEQUENCE DATABASE (GENBANK). NC_001539. 2000. Capturado em 05 mar, 2004. Online. Disponível na internet http://www.ncbi.nlm.nhi.gov/pubmed.

PARRISH, C.R. et al. Rapid antigenic-type replacement and DNA sequence evolution of canine parvovirus. Virology, v.129, p.401-414, 1991.

POLLOCK, R.V.; CARMICHAEL, L.E. Maternally derived immunity to canine parvovirus infection: transfer, decline, and interference with vaccination. Journal of the American Veterinary Medical Association, v.180, n.1, p.37-42, 1982.

PRATELLI, A. et al. Canine parvovirus (CPV) vaccination: comparison of neutralizing antibody responses in pups after inoculation with CPV2 or CPV2b modified live virus vaccine. Clinical and Diagnostic Laboratory Immunology, v.8, n.3, p.612-615, 2001.

REED, A.P. et al. Nucleotide sequence and genome organization of canine parvovirus. Journal of Virology, v.62, n.1, p.266276, 1988. 
SAGAZIO, P. et al. Antigenic characterization of canine parvovirus strain isolated in Italy. Journal of Virology Methods, v.73, n.2, p.197-200, 1998.

SENDA, M. et al. An improved hemagglutination test for study of canine parvovirus. Veterinary Microbiology, v.12, p.1-6, 1986.

TRUYEN, U. et al. Evolution of the feline-subgroup parvoviruses and the control of canine host range in vivo. Journal of Virology, v.69, n.9, p.4702-4710, 1995
TRUYEN, U. Evolution of canine parvovirus - a need for new vaccines? Veterinary Microbiology, v.117, n.1, p.9-13, 2006.

UWATOKO, K. et al. Rapid method utilizing the polymerase chain reaction for detection of canine parvovirus in feces of diarrheic dogs. Veterinary Microbiology, v.43, n.4, p.315323, 1995.

VEIJALAINEN, P.M.L. et al. Latex agglutination test for detecting feline panleukopenia virus, canine parvovirus, and parvoviruses of fur animals. Journal of Clinical Microbiology. v.23, n.3, p.556-559, 1986. 